\title{
QUATRO DÉCADAS DE PLANEJAMENTO ECONÔMICO NO BRASIL
}

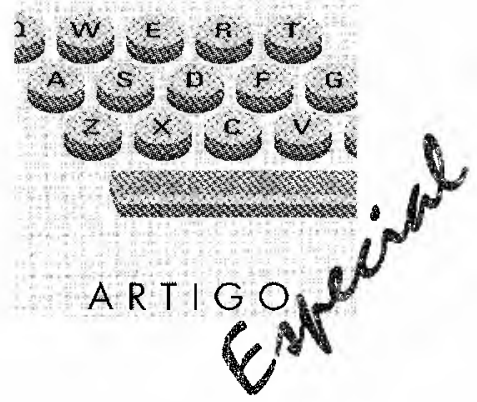

A experiência brasileira de planejamento econômico governamental federal: análise dos planos implementados e suas conseqüências.

Brazilian experience in central economic planning: analysis of the implementation and the consequences of the plans.

PALAVRAS-CHAVE:

Planejamento governamental. politica econômica, plano, desenvolvimento, estabilização.

\section{KEY WORDS:}

Public planning, economic policy, plan, development, stabilization.
* Doutora em Economia pela FEA/USP e Professora de Planejamento Socioeconômico da Administracão Pública da EAESP/FGV
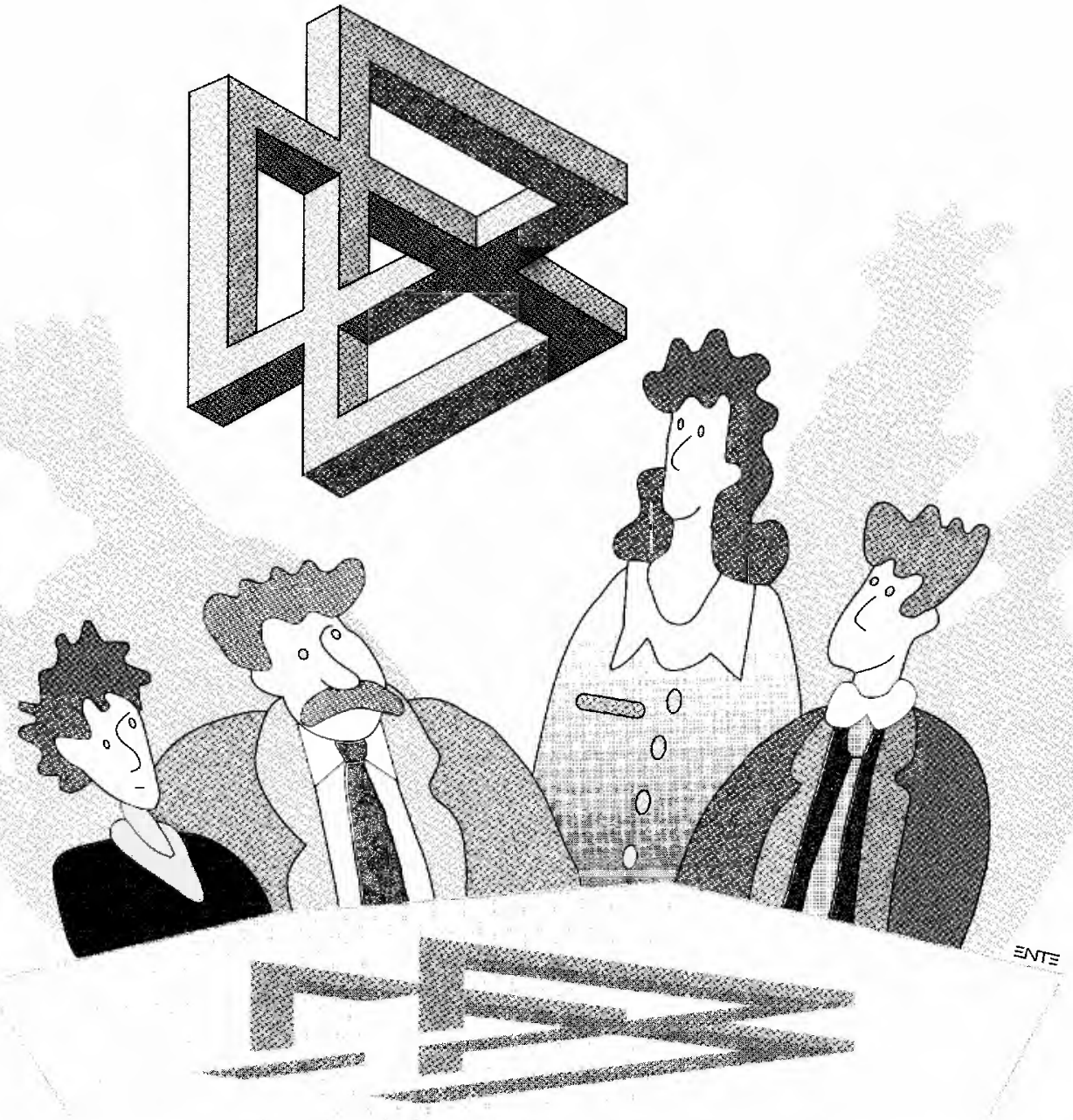
1. LAFER, Celso. The planning process and the political system in Brazil. A study of Kubits chek's target plan-1956-1961, Corneil University, 1970 (Tese de Doutorado).

2. TAVARES, M. C. Da substituição das importações ao capitalismo financeiro. Rio de Janeiro: Zahar, 1974.

3. Essa participação era de $35,1 \%$ do total da Formação de Capital Fixo no Brasil em 1950. atingindo $58,5 \%$ em 1960 , conforme LEFF, N. H. Politica e Desenvolvimento no Brasil. São Paulo: Perspectiva, 1979.
No Brasil, as tentativas iniciais de organizar a economia datam da década de 40 , resumidas no relatório Simonsen (1944-45), nos diagnósticos da Missão Cooke (1942-43), da Missão Abbink (1948), da Comissão Mista Brasil - EUA (1951-53) e no Plano Salte (1946). ' Porém, não consistiram em práticas efetivas de coordenaçāo global, restringindo-se a medidas setoriais ou de racionalização do processo orçamentário, como no último caso. A primeira experiência que considerava o processo global e contínuo de planejamento, e que foi efetivamente aplicada no país, data de 1956, com o Plano de Metas.

Este artigo examina a experiência brasileira de planejamento econômico, em nível federal, que compreende cerca de quatro décadas, analisando as propostas dos diferentes planos e os resultados de sua implementação. Observa ainda a condução da política econômica na busca da correção dos desajustes causados por fatores exógenos aos planos, originados por condiçōes internas ou externas ao país.

O período posterior à Segunda Guerra Mundial apresentou uma situaçăo de desgaste e forte recessão econômica nos países mais desenvolvidos, tradicionais produtores de bens de capital e demais produtos industrializados. Essa situação obrigou o Brasil - cujo processo de industrialização até então se desenrolava lentamente, configurando uma forte dependência de importações de bens de capital e de matérias-primas - a voltar-se com maior intensidade para a produção nacional de produtos industriais, em atendimento à demanda interna de bens de consumo, até então suprida pela importação. Iniciou-se, nesse período, um processo efetivo de substituiçấo de importações, baseado em uma diversificação industrial até então incipiente. ${ }^{2}$ Nessa ocasião, o modelo primário-exportador já levara o país a um processo de urbanização, que se fez acompanhar do desenvolvimento de uma infra-estrutura de servicos em atendimento a uma industrialização "tradicional" de alimentos, bebidas, vestuário, mobiliário etc.
A década de 50 caracterizou-se por uma queda mais acentuada das exportações do café a partir de 1954, aumentando o esforço para a reorientação da atividade econômica voltada para a indústria. O período 1956-61 foi assinalado pela introdução de um processo de planejamento efetivo das políticas econômicas governamentais a serem empreendidas, traduzidas no Plano de Metas. Foi prevista, para o apoio administrativo ao plano, a utilização de órgãos governamentais de

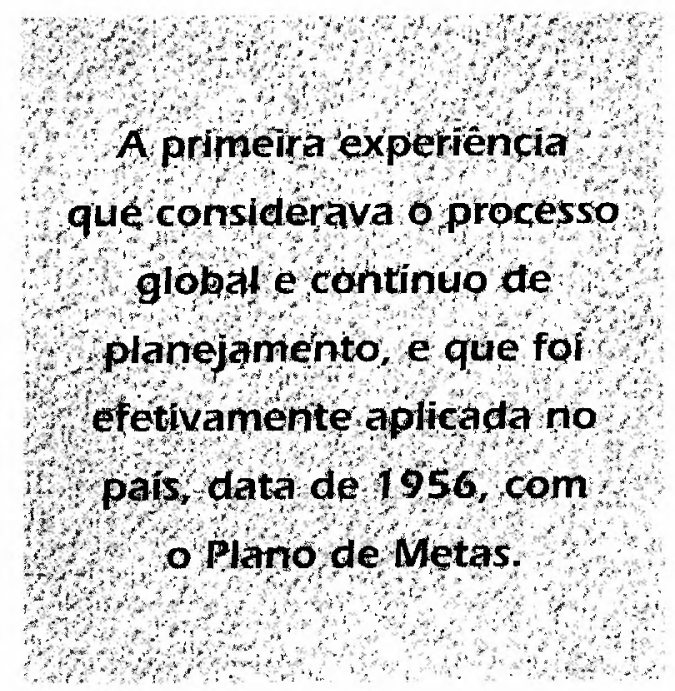

controle já existentes, como o BNDE Banco Nacional de Desenvolvimento Econômico (criado em 1952), a CACEX Carteira de Comércio Exterior do Banco do Brasil (1953), a SUMOC - Superintendência da Moeda e do Crédito (1945), bem como a criação de novas instituições, como, por exemplo, os Grupos Executivos, responsáveis pela concessão de incentivos ao setor privado estabelecimento de metas industriais, e o Conselho de Política Aduaneira.

A articulação entre o capital privado e o nacional, e entre o capital estrangeiro e o Estado, visualizada no plano, desempenhou papel importante no processo de industrialização que se acelerou acentuadamente no período. Este processo caracterizou-se por uma fase de intensa substituição de importações, desde que estava prevista a destinação de $43,9 \%$ dos recursos para implementação do plano, a importação de bens e de serviços. Esta fase distinguiu-se ainda pelo aumento da participação do governo nos investimentos, ${ }^{3}$ 
possibilitado pela entrada de capital estrangeiro privado e oficial para o financiamento do desenvolvimento de setores selecionados.

O plano, identificando setores, metas e objetivos a serem impulsionados, procurava eliminar "pontos de estrangulamento", que cram barreiras ao desenvolvimento, dando ênfase a atividades produtivas selecionadas. Para o setor de energia, era planejado $43,4 \%$ do total do investimento, a ser aplicado na elevação da capacidade de geração de energia elétrica, produção de carvão mineral e produção e refinação de petróleo. O setor transportes abrangeria $29,6 \%$ do total dos investimentos planejados, com vistas no reaparelhamento de ferrovias, dos serviços portuários e dragagens da marinha mercante e do transporte aeroviário. No setor alimentação, seriam alocados $3,2 \%$ do investimento plancjado, através do crescimento da capacidade estática da rede de armazenamento e de frigoríficos, da ampliação de matadouros industriais e da mecanização da agricultura, bem como do aumento da produção de fertilizantes. A indústria de base absorveria $20,4 \%$ do total de investimentos, particularmente na siderurgia, produçāo de aluminio, metais não-ferrosos, cimento, álcalis, celulose e papel, borracha, exportaçāo de minérios de ferro, indústria automobilística, de construção naval, mecânica e de material elétrico pesado. Finalmente $o$ setor educaçăo, contemplado com $3,4 \%$ dos investimentos, visava à formação de pessoal técnico especializado, orientado para as metas de desenvolvimento do pais. Estes investimentos tiveram repercussóes consideráveis no crescimento global da economia, através de seus efeitos multiplicadores. Saliente-se o fato de que contribuiram para esse desenvolvimento as taxas extremamente rápidas com que cresceu a demanda agregada, em virtude do aumento da renda real e do excesso de demanda refletido na inflação, que naquela década, situou-se entre $10 \%$ e $20 \%$ ao ano. Além disso, a elasticidade das condições de oferta interna permitiu que parte desse aumento da demanda se transformasse em aumento do produto real.

As políticas econômicas do plano visavam à proteção ao mercado interno, atra- vés de uma tarifa aduaneira altamente protecionista e da política cambial, que controlava o mercado de câmbio $c$ as taxas de câmbio diferenciadas, segundo um sistema de prioridades. Como visto, 0 desenvolvimento industrial foi fomentado nesse período pela ação do BNDE, que se concentrou nas indústrias de base (siderurgia) e na infra-estrutura (transportes e energia). Por outro lado, foi consideravelmente ampliada nessa época a participação direta do Estado nos investimentos em indústrias de base, que foram em grande parte financiadas pelas políticas monetária e fiscal expansionistas.

De um modo geral, os resultados da implementação do plano podem ser visualizados, não só através dos investimentos maciços no setor industrial de ponta, como também pela transferência do excedente gerado nesse setor para outras atividades terciárias de apoio, particularmente por meio de dispêndio do Estado ou do fornecimento de serviços complementares de infra-estrutura (embora esses investimentos de longa maturação comecem a se refletir com maior intensidade na década seguinte). Esta estrutura, que formou a base de apoio ao crescimento industrial dos últimos anos da década seguinte, já no final dos anos 50, havia incorporado parte da indústria de bens de consumo duráveis, de bens de capital e da indústria pesada, bem como de indústrias em substituição a importações de insumos básicos, máquinas e equipamentos, eletrodomésticos e automóveis.

\section{A DIFUSAOO E CASTALIZAOÃO DO DESENVOLYMENTO IMOUSTRIAL}

A década de 60 apresentou-se conturbada, do ponto de vista económico, com transformaçoes institucionais relevantes. A te o ano de 1961, o processo de substituiçăo de importações no país propiciou taxas médias de crescimento anual do produto em torno de $6,8 \%$. A partir de 1962, já se anunciava um período de estagnação, apresentando um crescimento menor em torno de $5 \%$, e no período posterior, até 1964, esse aumento cai para $3,4 \%$ ao ano. De fato, o processo de substituição das importações vinha se esgotando e a economia entrou numa fase de 
4. MARTONE, C Análise do Plano de Ação Econômica do Governo (PAEG). In: LAFER, B. M. Planejamento no Brasil. The planning process and the political system in Brazil. a study of Kubitschek's target plan - 1956-1961. Ithaca: Cornell University, 1970 (tese de doutoramento).

5. MACEDO, Roberto B. M. Plano Trienal Econômico, In: LAFER, B. M. Op. cit., p. 61.

6. MARTONE, C. Op. cit., p. 81. relativa estagnação, em vista de distorções no processo de desenvolvimento da etapa anterior, ${ }^{4}$ motivadas pelo processo inflacionário crescente que acompanhou o esforço de industrialização, pelo sentido desta industrialização (voltado para técnicas intensivas de capital e baixos índices de absorção de mão-de-obra), pelo aumento vertiginoso do setor público na economia e pela relativa estagnação do setor agrícola no país, do ponto de vista da produtividade.

Em 1963, foi publicado o Plano Trienal de Desenvolvimento Econômico e Social do Governo, abrangendo objetivos para o período 1963-65, visando a recuperar o ritmo de crescimento econômico observado no período anterior. Entre estes objetivos salientavam-se a consecução de uma taxa anual de crescimento da renda nacional de $7 \%$ ao ano, a redução progressiva da inflação, a distribuição da renda, a intensificação da ação governamental nos campos educacional, de pesquisa científica, tecnológica e de saúde pública, o levantamento dos recursos naturais, o refinanciamento da dívida externa e a unidade de comando do governo dentro de sua esfera de ação. A estratégia do plano baseava-se na elevação da carga fiscal, na redução do dispêndio público, na captação de recursos do setor privado no mercado de capitais, na mobilização de recursos monetários, com restrição do capital estrangeiro, e numa série de reformas de base, como, por exemplo, a reforma agrária. O Plano Trienal, portanto, explicitava a intenção de conciliar objetivos de crescimento, repartição e estabilidade, que, no entanto, mostraram-se conflitantes. As medidas postas em prática não impediram o fracasso da implementação do plano, ${ }^{5}$ observado pelo recrudescimento da taxa de inflação para $75 \%$, queda da taxa de crescimento do PIB - Produto Interno Bruto - do país para $1,6 \%$, aumento do déficit de caixa do Tesouro acima do programado e queda da taxa de investimentos.

Em 1964, foi instituído o Programa de Ação Econômica do Governo (PAEG) para o período de 1964-66, com o objetivo primordial de combater o processo inflacionário, além de acelerar o ritmo de desenvolvimento econômico do país, atenuar os desníveis econômicos setoriais e regionais, assegurar uma política de investimentos que aumentasse as oportunidades de emprego produtivo e corrigir a tendência a déficits do balanço de pagamentos. Interpretando a inflaçấo como de demanda e visando ao seu decréscimo, o governo deveria reduzir seu déficit de caixa, aumentando a carga tributária e atuando sobre a correção salarial, de modo a evitar a elevação da massa de renda à disposição dos assalariados acima do limite imposto pela capacidade de

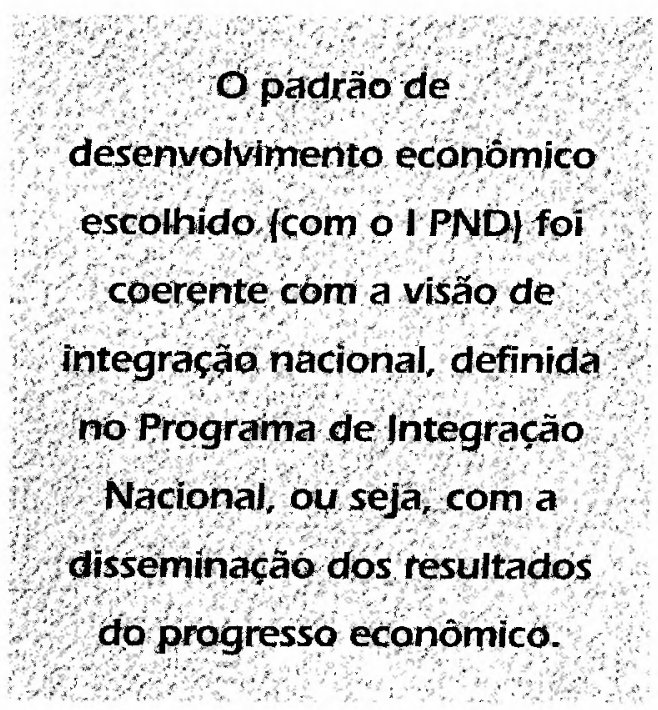

produção da economia. ${ }^{6}$ Por outro lado, o crédito à produção e consumo do setor privado seria contido e orientado no sentido de manter a liquidez real do sistema produtivo, mas ao mesmo tempo evitando a expansão não desejada nos meios de pagamento.

Neste período, foram efetuadas reformas institucionais e tributárias relevantes e ainda relativas ao mercado de capitais, ampliando o sistema de financiamento da economia. A reforma geral no Sistema Monetário-Creditício realizada em 1964 e a Reforma Financeira em 1965, visando à modernização financeira, criaram novos instrumentos de mobilização financeira e instituições especializadas no provimento de vários tipos de crédito, como: as financeiras, para o financiamento do consumo de bens duráveis; os bancos comerciais, para o fornecimento do capital de giro das empresas; os bancos de investimentos, para o fornecimento de recursos a longo prazo; o mercado de açōes, criando fundos de investimentos com dedu- 
ções do Imposto de Renda; o Banco Nacional da Habitação - BNH, com o fim de operar como agente financciro, com recursos dos trabalhadores. Essas reformas propiciaram, nos anos seguintes, um desenvolvimento muito rápido do sistema financeiro brasileiro, pois se, em 1964, os ativos monetários (papel-moeda e depósitos à vista) em poder do público correspondiam a $88 \%$ dos haveres financeiros, em 1978 situavam-se em $31 \% .{ }^{7}$ Apesar desses resultados, as medidas levadas a efeito não se fizeram sentir de imediato, pois os objetivos e metas propostos pelo plano não foram alcançados.

Em 1967, foi publicado o Programa Estratégico de Desenvolvimento para o período 1968-70, apresentando como objetivos básicos o fortalecimento da empresa privada, visando à aceleração do desenvolvimento econômico, concomitantemente à estabilização gradativa do comportamento dos preços, consolidação da infra-estrutura pelo governo, expansão das oportunidades de emprego, fortalecimento e ampliação do mercado interno. Como condições para a consecução destes objetivos estavam a manutenção do controle do balanço de pagamentos e a realização de reformas econômicas e sociais, a fim de modernizar as estruturas institucionais e impedir o agravamento das disparidades regionais e setoriais existentes. As condições para a retomada do crescimento eram favoráveis devido a fatores como a capacidade ociosa das empresas, a demanda global que se encontrava reprimida, a disponibilidade de mão-de-obra desempregada e a possibilidade de serem estimulados os investimentos públicos e privados no sentido de modernização, apoiados pela reorganização do sistema financeiro. Como conseqüência das medidas de estímulo do programa, observou-se, a partir de 1968, a queda da taxa de inflação e o aumento da taxa de crescimento do produto.

Em 1971, é submetido ao Congresso Nacional o I Plano Nacional de Desenvolvimento Econômico (I PND) para o período 1972-74. As estratégias e prioridades definidas tinham como objetivos primordiais a manutenção do nível global do PIB, a continuação do combate à inflação, o equilíbrio da balança de pagamentos e a melhor repartição de renda.
Seriam implantados instrumentos no sentido de permitir a modernização da empresa nacional, do sistcma financeiro e do mercado de capitais. A par disto, seriam criados programas específicos, como a Política de Tecnologia Nacional, visando ao avanço tecnológico, o Programa Petroquímico, o Programa de Construção Naval, o Programa Básico de Energia Elétrica, os Corredores de Transportes, o Programa de Comunicações e o de Mineração.

O padrão de desenvolvimento econômico escolhido foi coerente com a visão de integração nacional, definida no Programa de Integração Nacional, ou seja, com a disseminação dos resultados do progresso econômico a partir de centros de crescimento regional e de seus efeitos multiplicadores, baseando-se nas vantagens comparativas do país. Por outro lado, este padrão, fundamentado na modernização da tecnologia, tornou a economia dependente de recursos externos, apoiada em crescente endividamento público e privado. O Estado subsidiou a formação de capital na indústria, através de isenções ou reduções da tarifa aduaneira e dos impostos IPI - Imposto sobre Produtos Industrializados e ICM - Imposto sobre Circulação de Mercadorias, que incidiam sobre a importação de máquinas e equipamentos destinados à indústria, de acordo com projetos aprovados pelo Conselho de Desenvolvimento Industrial (CDI) ou outros órgãos regionais de desenvolvimento. Além disto, foram instituídos subsídios embutidos nos financiamentos a longo prazo para investimentos industriais, pelo $\mathrm{BNDE}$, que consistiam em correção monetária inferior às taxas de inflação observadas. Paralelamente, a instituição de incentivos fiscais, administrados por órgãos regionais de desenvolvimento, pretendia impulsionar os investimentos em regiões menos desenvolvidas (particularmente o nordeste), transformando a agricultura da região semi-árida e assegurando um processo de industrialização auto-sustentado, e, na Amazônia, ampliando a fronteira agrícola.

Essas políticas permitiram que a retomada do crescimento econômico, verificada a partir de 1968, continuasse a aceleração até 1973 , quando se observaram ta-
7. TAVARES, M. C. 0 sistema financeiro e o ciclo de expansão recente. Desenvolvimento Capitalista no Brasil, n. 2, São Paulo: Brasiliense, 1983; LESSA, Carlos. Quinze anos de Política Econômica. São Paulo: Brasiliense, 1981. 
xas médias anuais do produto de $13 \%$, entre 1971-73. As reformas tributárias e financeiras anteriormente verificadas, permitiram a eliminação do déficit de caixa do Tesouro Nacional e um financiamento dos investimentos sem efeitos inflacionários. Além do mais, foram criadas novas instituiçōes para a formação compulsória de poupança, como o Programa de Integração Social (PIS-PASEP), o Fundo de Garantia por Tempo de Serviço (FGTS) e novos instrumentos de captação de recursos ao público, como as letras de câmbio, as Obrigações Reajustáveis do Tesouro Nacional (ORTN), as cadernetas de poupança, os Certificados de Depósito Bancário (CDB) etc. Esses novos dispositivos possibilitaram a folga de recursos financeiros em apoio aos investimentos maciços em infraestrutura e em capital fixo.

Observou-se uma rápida

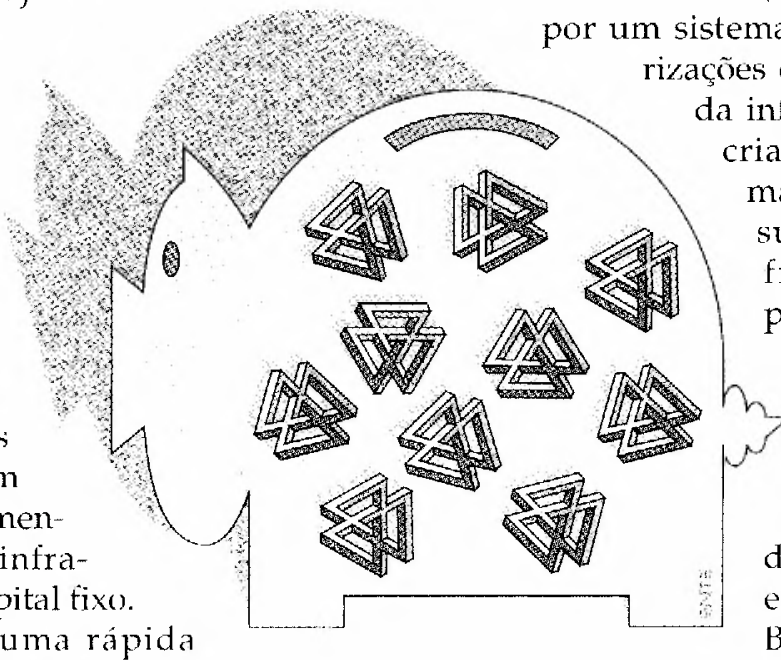
difusão do mercado para produtos industrializados, que resultou da expansão da demanda interna e também da diversificação das exportações. A política governamental expansionista, em apoio à expansão do mercado interno, manifestou-se pelos investimentos em infra-estrutura econômica e sociàl, transportes, comunicações, energia, urbanizaçăo esaneamento básico, e ainula por meio de investimentos diretos de empresas estatais em indústrias de base (particularmente de mineração), exploração de petróleo, fertilizantes, quimica, petroquimica e siderúrgica e em indústrias de armamentos e aeronáutica. Por outro lado, o Sistema Financeiro de Habitaçăo (SFH), criado anteriormente em meados dos anos 60, constituido do Banco Nacional da llabitação (BNI), serviu-se, neste periodo, dos instrumentos de captação e empréstimos criados para impulsionar a indústria de construção civil e as indústrias fornecedoras de insumos a este setor.

$\Lambda$ partir desses instrumentos de política econômica, observou-se uma expansão na demanda de consumo, como resultado da elevação do nível de emprego e do aumento da massa salarial, e das facilidades de financiamento pelo crédito direto ao consumidor. $\mathrm{O}$ crescimento industrial do periodo 1968-73, portanto, manifestou-se como o auge do ciclo de expansão, liderado pelas indústrias de bens de consumo duráveis (eletrodomésticos e automóveis).

Também no período, as exportaçōes de produtos manufaturados foram estimuladas particularmente pela desvalorização cambial anterior (agosto de 1968), c por um sistema de minidesvaloinflaçào, ao lado da riação de um sistema de incentivos $\mathrm{e}$ subsídios fiscais e financeiros à exportação. Foi incentivada também a criação de trading companics e programas especiais de produção para exportação pela BEFIEX - Comissão para Concessão de Beneficios Fiscais a Programas Especiais de Exportaçăo (criada em 1972). Esses incentivos foram favorccidos pelo dinamismo do comércio internacional que se verificava até meados dos anos 70 .

0 aumento dos preços internacionais do petróleo, em fins de 1973, teve como conseqüencias uma crise internacional e reajustes nas economias mundiais, gerando uma série de novos condicionantes à política econômica que vinha sendo implantada no país. O 1I PND, elaborado nessa conjuntura para o periodo de 1975-79, previa um programa de investimentos condizentes com uma taxa média de crescimento de $10 \%$, visando à substituição de importaçóes como estratégia. Tendo como diretriz primordial o crescimento economico acelerado e contínuo e como retórica reafirmar o país como potência emergente, o plano estabelecia, como objetivos adicionais, a continuação da política anti-inflacionária pelo método gradualista, a manutenção do equilíbrio no balanço de paga- 
mentos e a realização de uma política de melhoria na distribuição pessoal e regional de renda. Foram formuladas estratégias para o desenvolvimento industrial e agropecuário, a integração nacional e internacional e o desenvolvimento social.

A crise econômica internacional surgida com o "choque do petróleo" não alterou os objetivos de desenvolvimento acelerado do plano. Em consonância a estes objetivos, o Brasil recorreu ao endividamento externo, reagindo à nova situação mundial. Para isto, contribuiu a adoção de políticas contracionistas em países desenvolvidos, o que favoreceu o estado de liquidez no mercado financeiro internacional e possibilitou a continuação do crescimento do produto a taxas elevadas no país. Essa conjuntura foi apoiada ainda por uma política de preços internos do petrólco, que gerou aumentos pouco expressivos deste insumo, o que retardou a queda da atividade econômica no país, em relação à dos outros países. Por outro lado, o segundo choque do petróleo em 1979, representado por um aumento de $37,9 \%$ nos preços do produto em relação ao ano anterior e de $73,1 \%$ no ano de 1980 , foi acompanhado ainda por políticas de ajustes, de modo a permitir que os repasses internos dos preços fossem inferiores aos externos, apresentando-se abaixo da inflação americana, com declínio do preço real do barril. Esta política permitiu a persistencia das taxas ascendentes da utilização desse insumo na indústria e em grande parte dos transportes.

A incongruência da implementação do plano original, sem as reformulaçōes necessárias para enfrentar as pressões exógenas surgidas com a nova situação mundial, não apenas comprometeu as metas definidas, como também ocasionou o agravamento das contas cxternas e das tensões inflacionárias. A adoção de uma política de stop and go, ao longo do período do plano, manifestando-se por anos de expansão e recrudescimento da inflação (1976-78) e anos de contenção do crescimento (1975 e 1977), não impediu a aceleração da inflação, o aumento do déficit público, do déficit em transações correntes na balança comercial e do endivi- damento externo bruto, que de US $\$ 21$ bilhões em 1975 elevou-se para US\$ 49,9 bilhões em 1979.

Além do mais, o ano de 1980 caracterizou-se pela expansão da demanda agregada, ocasionada pela promulgação da lei salarial de setembro de 1979, que fixou reajustes semestrais de salários baseados no Índice Nacional de Preços ao Consumidor - INPC e o prêmio de produtividade aos assalariados, situado em $7 \%$ em média, em $1980 .{ }^{8}$ A continuada taxa de crescimento do produto, que no período se situou em média em $9,4 \%$ no país, deveu-se em parte à continuidade das exportações, que não refletiram o desaquecimento da demanda internacional após 1974, chegando mesmo a apresentar crescimento. Isto se verificou em conseqüencia das medidas econômicas que compuseram uma "mini-reforma cambial", as quais estimularam as exportações, bem como da intensificação das desvalorizaçoóes cambiais e da maxidesvalorização no final de 1979, de maneira a alterar a paridade do poder de compra do cruzeiro. Ainda em 1980, a prefixação cambial resultou em vantagens nos preços das matérias-primas importadas, contribuindo para a taxa de crescimento dessas importações.

As altas taxas de crescimento do PIB, no período do II PND, refletiram, por um lado, o atendimento de grandes obras públicas que continuaram a impulsionar a atividade industrial e financeira, tais como a da Usina Hidroelétrica de Itaipu, da Ferrovia do Aço, do Metrô em São Paulo, da Usina Nuclear de Angra dos Reis e outras. Além do mais, a partir de 1974, foram ampliadas as linhas de crédito através de empresas subsidiárias do Banco Nacional de Desenvolvimento Econômico - BNDE, representadas pelos órgãos de Financiamento da Indústria de Base - FIBASE, Investimentos Brasileiros S.A.- EMBRAMEC e Agência Especial de Financiamentos Industriais - FINAME. Paralelamente, foram adotadas medidas de restrições às importações de máquinas c equipamentos, favorecendo as indústrias nacionais de bens de capital. A implementação acima mencionada dos projetos de obras governamentais foi responsável pela demanda de parte da produção das outras indústrias de base, produ-
8. MACEDO, R. B. M. Politica salarial e inflação: a experiencia brasileira recente. São Paulo: IPE/USP, 1981. 
9. CARNEIRO, D. D. O Terceiro choque: é possível evitar-se a recessão? In: ARIDA, P. (org.) Dívida externa, recessão e ajuste estrutural. Rio de Janeiro: Paz e Terra, 1982. toras de bens intermediários, como as de minerais não-metálicos, metalúrgica, química e madeira.

Para o comportamento dos preços, que revelaram uma aceleração em seu crescimento a partir de 1974, acentuada em 1979, contribuíram vários fatores, que podem ser resumidos como: encarecimento das matérias-primas devido ao aumento no preço dos derivados do petróleo; crescimento das exportações, que afetou os preços internos; elevação da taxa de juros médios pagos interna e externamente; aumento paralelo da demanda interna em 1980, decorrente da política salarial; maxidesvalorização verificada no final de 1979 , visando a corrigir desníveis cambiais e crescimento dos custos de produção em 1980, em virtude da política salarial, que foi repassada aos preços de bens e serviços.

A alta acelerada de preços externos e internos já acentuada em 1979, a evolução da taxa externa de juros em 1980 para níveis inusitados, onerando ainda mais o pagamento da dívida externa do país, bem como a manutenção da queda da atividade econômica no âmbito internacional, associada à restrição do crédito externo, já delineavam (desde o final dos anos 70 ) a tendência para a restrição do ritmo de produção global. Para isto, concorreram a diminuição da demanda interna, em conseqüência de políticas salariais sucessivas que reduziram consideravelmente o poder de compra da população, e outras políticas governamentais de ajustes, que passaram a ser postas em prática a partir de 1980.

O III Plano Nacional de Desenvolvimento, formulado para o período de 1980-85, tinha seus objetivos substancialmente alterados em relação aos planos anteriores, visando ao reequilíbrio das contas cambiais e do balanço de pagamentos, bem como ao controle da taxa de inflação. O rápido processo de contenção da atividade econômica, que decorreu da elevação drástica da taxa de juros doméstica e da tentativa de controle do déficit do setor público com a desaceleração dos investimentos, visava a conter a acelera- ção da inflação e diminuir o déficit das contas externas do país. Paralelamente a isto, a queda da produção industrial, acompanhada de uma redução das importações, contribuiu para a obtenção de um superávit da balança comercial do país em 1981. No entanto, já no ano seguinte, a recessão verificada nos países importadores de produtos brasileiros provocou a retração destes mercados e a conseqüente desaceleração das exportaçöes. Este fato neutralizou as medidas

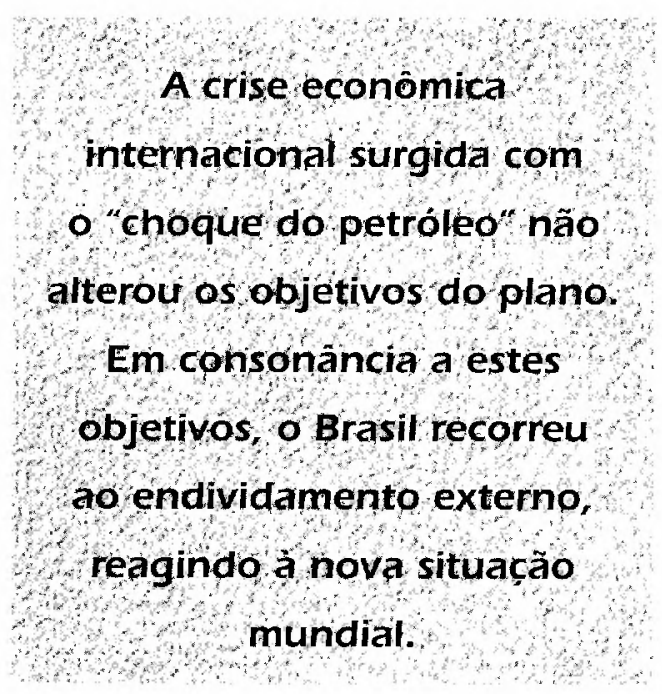

contracionistas internas, que visavam a reduzir as necessidades de empréstimos externos. ${ }^{9}$

O desequilíbrio da balança de pagamentos do país resultou, no período 1982-83, em uma situação em que mais de $80 \%$ das receitas cambiais em transações correntes eram destinadas ao serviço da dívida externa. Além do mais, a partir de 1982, observou-se uma retração do sistema financeiro privado internacional com relação à renegociação das dívidas externas de 25 países, entre os quais o Brasil, o que conduziu o país a um estado de iliquidez. As medidas macroeconômicas que visavam a reduzir o nível da demanda no mercado interno, com o intuito de gerar excedentes de exportação, incluíam uma política cambial agressiva e a manutenção de incentivos e subsídios no sentido de favorecer a produção para exportação, enquanto as atividades voltadas para o mercado interno tiveram seus preços controlados pelo Conselho Interministerial de Preços (CIP). As importa- 
ções, por sua vez, tiveram um controle mais rígido, particularmente por meio de barreiras não-tarifárias, e a isto se associaram uma política monetária rígida e restrições ao crédito, como desestímulo ao investimento privado.

De um modo global, a economia brasileira apresentou uma evolução positiva em alguns ramos dinâmicos da indústria, do setor financeiro e das comunicações em 1982, o que evitou uma queda mais acentuada do produto nacional. Para isso colaborou, ainda, a política salarial reformulada, que naquele ano contribuiu para sustentar o nível do consumo agregado, alimentado pelo crescimento dos empréstimos financeiros. No entanto, grande parte do aumento da demanda interna, em valores nominais, foi diluída pela inflação explosiva. No ano de 1983, observou-se sucessivas revisões da política salarial, que redundaram em média na perda do poder de compra do assalariado em cerca de $20 \%$. Ao lado disto, o aumento da taxa de desemprego levou a uma maior queda da demanda agregada. Por outro lado, o nível de poupança interna reduziu-se, diminuindo os recursos para financiamento do setor privado, mantendo elevadas as taxas de juros. Com relação à balança comercial, as exportaçôes ainda superaram as importaçŏes, que foram consideravelmente reduzidas no ano, diante da contenção da demanda pelas indústrias. Os setores mais afetados da indústria foram o de bens de capital, com a queda drástica das encomendas e aumento da capacidade ociosa, e o da construção civil com a diminuição do poder aquisitivo da população, por um lado, e dos investimentos públicos por outro.

No tocante à inflaçāo, sua aceleração deveu-se em parte aos "choques de oferta" devido às enchentes do sul, secas no nordeste, maxidesvalorização e elevação corretiva de preços administrados com a retirada de subsídios diretos. A par disto, a política monetária permitia a expansāo da moeda no sentido de ajustar a liquidez do sistema ao aumento dos preços. No mercado financeiro várias medidas foram tomadas com o intuito de reduzir o volume de recursos do sistema financeiro, provocando retração na oferta de crédito.
Após três anos consecutivos de recessão, de 1981 a 1983, em que se expandiu o atraso tecnológico brasileiro em relação aos países industrializados, esperava-se em 1984 o aprofundamento da queda da atividade. Porém, a economia brasileira retomou um novo ciclo de crescimento, a partir da ocupação dos fatores de produção que se encontravam ociosos, verificando-se naquele ano um crescimento da ordem de $4,5 \%$ do PIB. Esta retomada das atividades continuou em $1985 \mathrm{com}$ maior intensidade, permitindo o pagamento integral dos juros da dívida externa e a maior taxa de crescimento histórico do país. Para isto contribuíram a queda dos preços do petróleo e a diminuição das taxas de juros internacionais, que, concomitantes à melhoria do nível de emprego interno, do aumento do déficit público e da remonetização acelerada da moeda, permitiram a intensificação do nível de utilização da capacidade industrial e a elevação dos salários reais.

A reversão da conjuntura recessiva ocorreu principalmente como conseqüência da recuperação das economias americana (principal mercado das exportações brasileiras), japonesa e dos países da OECD - Organisation for Economic CoOperation and Development, com reflexos no aumento das exportações brasileiras - facilitado pela maxidesvalorizaçāo do cruzeiro em fevereiro de 1983 - que redundou em um superávit comercial acentuado. Porém, neste período, observou-se a ausência de uma política industrial vinculada a uma estratégia de desenvolvimento científico e tecnológico a médio e curto prazos, tratando-se os problemas de competitividade internacional da indústria através de medidas a curto prazo, que desfavoreceram o mercado interno. Apenas o setor da indústria de informática recebeu apoio a partir da política de reserva de mercado, o que contribuiu para a implantação de empresas privadas nacionais, voltadas para o segmento de mini e microcomputadores, que, no entanto, mostraram-se pouco competitivas em nível internacional.

Entre 1985 e 1987, a política governamental procurou formular estratégias para o desenvolvimento industrial, que no entanto não foram devidamente implementadas. Além do mais, as metas de 
apoio à modernização tecnológica e científica industrial foram afetadas pela política fiscal baseada no aumento da folha real de salários do governo federal em cerca de $40 \%$ no ano, e com o congelamento de preços públicos, o que resultou na expansão da dívida interna real do setor público. Além disso, em novembro de 1985, o governo alterou a sistemática do Imposto de Renda para bases correntes, conduzindo a uma queda na sua arrecadação que se faria sentir no início do ano seguinte. Como conseqüência, no princípio de 1986, havia a percepção de que a inflação, que se estabilizara no patamar de $220 \%$ no ano anterior, tendia a um crescimento que ameaçava se tornar incontrolável.

A partir do diagnóstico de que a inflação era mormente causada por componentes inerciais, foi decretado o Plano Cruzado em fevereiro de 1986, instituindo um novo padrão monetário (o cruzado), o congelamento total de preços e tarifas de bens e serviços de preços e fixidez cambial. Foi reestabelecido o valor real dos salários, concedido um abono salarial de $8 \%$ e o seguro-desemprego. Num primeiro momento, as novas medidas provocaram uma forte pressão da demanda, devido à redistribuição de renda ocorrida e o aumento da massa salarial, com um boom de consumo e aceleração do crescimento do emprego, porém não de investimentos, o que agravou as deficiências da infra-estrutura já existentes. Porém, o prolongado congelamento dos preços e o aquecimento da demanda resultaram em desequilíbrios entre oferta e demanda e na estrutura dos preços relativos, reduzindo o nível de poupança interna e as reservas cambiais, a par da excessiva monetização da economia. Ocorreu uma série de gargalos na produção, com desabastecimento de produtos resultando em ágios e filas e incentivando a importação de produtos, o que eliminou o ajuste externo. Verificava-se, paralelamente, a acumulação de um atraso da taxa de câmbio e observou-se, no final do ano, um movimento abrupto de perda de reservas com semiparalisação das exportações. O saldo comercial decresceu consideravelmente, resultando em queda de reservas cambiais, e o país entrou em moratória.
O Plano Cruzado 2 foi decretado em novembro de 1986, com o objetivo de conter a demanda com medidas de desaceleração do crescimento e significativa elevação da carga tributária indireta, visando a evitar maior fuga de divisas, concomitantemente ao reajuste de alguns preços em taxas muito acentuadas e à liberação da taxa de juros. No entanto, o plano não logrou resolver esses problemas, resultando em uma explosão de preços, que apontou para a perspectiva

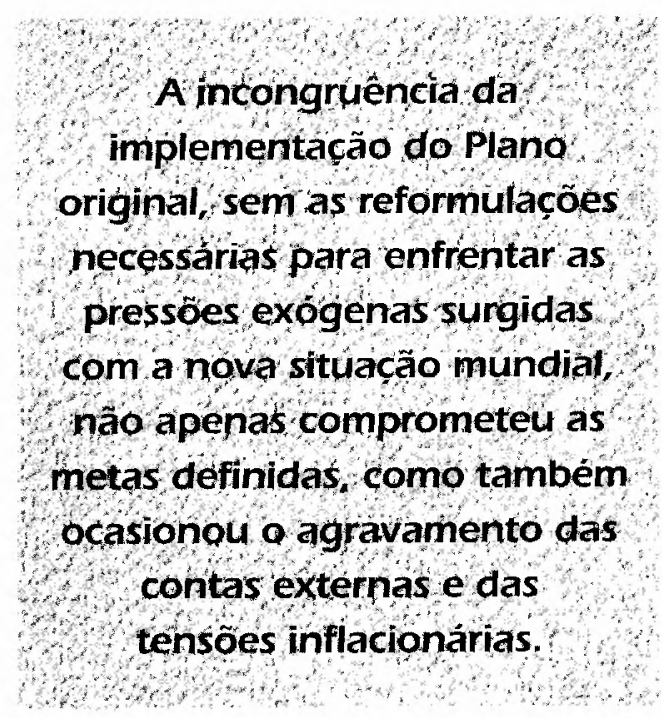

de um novo patamar inflacionário, superior ao do início dos anos 80, e para um aumento acentuado do déficit público.

Em 1987, foram definidos novos programas de política industrial que visavam a uma retomada de investimentos na área de insumos básicos (petroquímica, papel e celulose, fertilizantes e metalurgia) e da indústria automobilística, que no entanto não tiveram resultados consideráveis, apenas registrando investimentos razoáveis nos setores de papel e celulose e petroquímico, em função do mercado externo favorável. Em meados de 1987, a Comissão de Política Aduaneira (CPA) elaborou a reforma da tarifa aduaneira, propondo a eliminação dos regimes especiais de importação, a incorporação das diversas taxas na alíquota de importação (Imposto sobre Operações Financeiras - IOF, Adicional de Frete para Renovação da Marinha Mercante AFRMM e Taxa de Melhoramento de Portos - TMP) e a redução generalizada das tarifas, com a redução da média e das 
disparidades em torno dessa média. No entanto, antes de sua implementação, a reforma tarifária foi suspensa.

Em junho de 1987, foi decretado pelo governo um novo plano de estabilização de emergência, conhecido como Plano Bresser, em que foi mantido o congelamento de preços, objetivando o controle da demanda agregada através da compressão salarial e do ajuste fiscal. O plano visava a diminuir o déficit público por meio da correção prévia dos preços e tarifas públicas, redução de subsídios e de gastos de capital. Com relação às contas externas, foi tentado o realinhamento da taxa de câmbio, com minidesvalorizações, e foi mantida a moratória, que no entanto não propiciou acordo com os credores externos ou a normalização do fluxo de capitais. O crescimento contínuo da inflação e o controle das finanças do governo limitaram o apoio ao plano.

O Plano Maílson, instituído em janeiro de 1988, baseou-se principalmente na busca da redução do déficit fiscal tentando evitar a hiperinflação e possibilitar a renegociação da dívida externa, com a efetivação de um acordo em agosto de 1988. As principais medidas de contenção fiscal foram o corte de $5 \%$ dos gastos de custeio e pessoal da administração direta e indireta, o congelamento do montante do crédito aos estados e municípios, a suspensão de reajustes salariais do funcionalismo público, paralelamente ao estímulo à exoneração e às aposentadorias voluntárias dos funcionários federais e de autarquias. A criação de Zonas de Processamento das Exportações (ZPEs) também foi sugerida e discutida, em 1988, no sentido de fomentar o desenvolvimento de regiões desfavorecidas. No entanto, as medidas previstas foram sujeitas a críticas, por parte de especialistas, que demonstraram a impropriedade de aplicação nas condiçôes do país no período, e sua ineficiência como instrumento de desenvolvimento tecnológico. A principal crítica se referia à baixa efetividade de atração de capital estrangeiro, face às tendências vigentes de movimento dos capitais internacionais e ao baixo grau de encadeamento de atividades, o que não favoreceria o desenvolvimento regional.

No entanto, a inflação tendia a acelerar-se e, em janeiro de 1989, foi instituído o Plano Verão, baseado no congelamento, na reforma monetária e na tentativa de desindexação da economia. As taxas de juros foram mantidas altas, o que elevou consideravelmente a dívida pública interna, dificultando o controle da expansão monetária. As OTNs - Obrigações do Tesouro Nacional - foram extintas, substituídas por um novo indexador - Nota do Tesouro Nacional (NTN) - e, logo cm seguida, pelos Bônus do Tesouro Nacional (BTN). Com relação às contas externas, o câmbio foi fixado em US\$ 1 por $\operatorname{Cr} \$ 1$, o que tornou o dólar barato, resultando na remessa de capitais ao exterior, sem a entrada de novos empréstimos. $O$ saldo comercial caiu e em junho foi instituída uma minidesvalorização de $12 \%$ com centralização do câmbio, o que culminou em uma nova moratória em setembro. No segundo semestre, foi reintroduzida, pelo Congresso, a indexação dos salários, e, em dezembro, o país se encontrava ameaçado por hiperinflação.

O Plano Collor I, anunciado em março de 1990, combinava uma reforma monetária profunda (que recriava o cruzeiro), prefixação da correção de preços e salários, câmbio flutuante, tributação ampla e pesada sobre aplicações financeiras, enxugamento drástico do dinheiro em circulação no país, fechamento de empresas e órgãos públicos e demissão de funcionários. Dos recursos mantidos em conta corrente e em caderneta de poupança, apenas Cr\$ 50 mil puderam ser convertidos em cruzeiros e sacados, o restante permaneceu depositado no Banco Central durante 18 meses, com correção monetária e juros a $6 \%$ ao ano. Os depósitos a prazo, overnight e fundos de curto prazo também tiveram seus saques limitados. A CACEX - Carteira de Comércio Exterior - passou a se subordinar diretamente ao Ministério da Economia, que restringiria suas atividades para acompanhar um programa de liberação das importações visando a acabar com controles e restrições e manter apenas um sistema adequado de tarifas. Foi planejada a aceleração do processo de privatização de estatais, e as instituiçōes financeiras teriam de aplicar compulsoriamente parte do seu patrimônio em títulos de privatização criados, a serem posteriormente trocados por participação nas estatais, 
quando ocorressem leilões de privatizacão. A tributação indicava um aumento do IPI de vários produtos, taxação mais pesada sobre o lucro do setor agrícola e a instituição do Imposto sobre Operações Financeiras (IOF) sobre aplicações como ouro, ações, títulos em geral e caderneta de poupança. Seriam extintos os benefícios fiscais de redução de Imposto de Renda das pessoas jurídicas e os incentivos à exportação.

$\mathrm{O}$ congelamento dos preços públicos agravou a situação das estatais e a recuperação das tarifas acabou pressionando a inflação. Por sua vez, a necessidade de socorrer o caixa dos bancos impediu um controle eficiente da moeda. O bloqueio da dívida pública possibilitou a administração do orçamento federal, porém os cortes dos gastos foram limitados $\mathrm{e}$, a partir do início de 1991, observaram-se dificuldades no controle das contas públicas, devido à recessão, à continuação da alta da inflação e à perspectiva da posterior devolução do dinheiro bloqueado. A política industrial, delineada no início do novo governo, não tomou o fôlego necessário. $\mathrm{O}$ anunciado pacote de medidas, sob o nome de Programa de Apoio à Capacitação Tecnológica da Indústria, previa um crescimento nos investimentos em pesquisa tecnológica, que passariam de $0,5 \%$ do PIB, em 1990 , para $1,3 \%$ até 1994, embora ainda se situando aquém dos parâmetros dos países desenvolvidos (em torno de $2,5 \%$ ). A nova e tímida política industrial recorreu ao fim dos subsídios governamentais e a uma política de liberalização das importações para estimular a capacidade real de modernização industrial brasileira e atender os objetivos de elevação da competitividade e da produtividade. No entanto, a restrição da atividade econômica, subproduto das medidas de ajustes fiscal e monetário, a carência de recursos e o clima de incertezas quanto à condução da política econômica pelo governo bloquearam o avanço de investimentos consideráveis por parte de empresas privadas e estatais.

O Plano Collor II, em janeiro de 1991, objetivava refrear a corrida da inflação. As medidas previam o congelamento de preços e salários, a unificação das datasbase de reajustes salariais (os salários passariam a ser corrigidos duas vezes

por ano, em janeiro e julho, para todas as categorias profissionais), a conversão pela média real dos últimos doze meses, o fim do BTN e do BTNF (visando a desindexar a economia), o fim do overnight e a criação de um fundo de títulos federais e estaduais, a criação da Taxa Referencial de Juros (TR), a aplicação de uma tablita para contratos anteriores ao plano, o aprofundamento do aperto monetário e fiscal e finalmente um tarifaço para atualização das tarifas e preços públicos (tari-

O II Plano Nacional de

Desenvolvimento, formulado para o período de 1980-85 tinha seus objetivos substancialmente alterados em relação aos planos anteriores, visando ao reequilibrio das contas cambiais e do balanco de pagamentos, bem como o controle da taxa de inflação.

fas portuárias, nafta, gás de cozinha, gasolina, álcool e energia elétrica). No entanto, a inflação volta a crescer rapidamente já a partir de abril, situando-se no final da gestão presidencial em um patamar de $23 \%$ ao mês. Neste período, a economia apresentava uma situação de aprofundamento da recessão econômica, aumento do desemprego, queda dos salários e da massa salarial. Por outro lado, a recessão interna levou as empresas ao mercado externo e inibiu as importações, o que resultou em saldos superavitários na balança comercial e no aumento de reservas cambiais. Por outro lado, as elevadas taxas de juros do mercado interno, consideravelmente superiores às internacionais, favoreceram um movimento de entrada de capitais especulativos no país. A contrapartida foi a necessidade de emissão de cruzeiros, que provocou expansão dos meios de pagamento e pressões nas áreas fiscal e monetária.

Na gestão presidencial seguinte, a busca da organização da economia priorizou 
o ajuste do setor público, que se objetivou através do denominado Plano FHC1 Fernando Henrique Cardoso. A proposta do plano envolvia o corte de despesas da União (em um montante de US\$ 6 bilhões em 1993), o ajustamento das contas dos estados e municípios, o equilíbrio dos bancos oficiais estaduais e a aceleração do programa de privatizações. Dificuldades políticas impediram a consecução satisfatória das medidas previstas e, em dezembro de 1993, foi apresentado um Programa de Estabilização Econômica, que passou a ser conhecido como FHC2, a ser implementado em três tempos. A primeira fase, de ajuste das contas do governo, foi viabilizada a partir da aprovação pelo Congresso Nacional, da emenda constitucional de revisão que criou o Fundo Social de Emergência, que garantiria os recursos para este ajuste, advindos de impostos e contribuições, sendo a eliminação do déficit orçamentário complementada através de outras medidas como vendas de ações e de participações acionárias depositadas no FND - Fundo Nacional de Desenvolvimento -, esforço adicional de arrecadação e redução nas dotações orçamentárias para outros custeios e capital dos poderes Legislativo e Judiciário. A segunda fase se refere à criação de um padrão estável de valor, denominado Unidade Real de Valor (URV), para servir como moeda confiável para denominação de contratos e obrigações, bem como para referenciar preços e salários. $\mathrm{O}$ objetivo da introdução da URV seria romper a inércia inflacionária, cortando o vínculo com a inflação passada e reduzindo as incertezas e expectativas negativas quanto à inflação futura, uma vez que este indexador refletiria a inflação presente. A terceira fase do programa se relaciona à transformação desse novo padrão de valor em uma nova moeda nacional de poder aquisitivo estável: o real. Esta transformação deverá assegurar à moeda nacional a capacidade de servir como meio de pagamento e substituir, como reserva de valor, as variadas formas de moeda remunerada existentes.

No momento da redação deste trabalho, a nação encontra-se envolvida na implementação da segunda fase do programa, relacionada à substituição da utilização de cruzeiros reais pela URV e nos ajustamentos necessários à resolução dos conseqüentes conflitos comuns entre os agentes econômicos de várias classes, de interesses diversos, quer se situem como trabalhadores, produtores, consumidores ou governo.

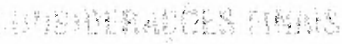

Ao analisar-se as quatro décadas de planejamento no Brasil, é necessário acrescentar-se alguns aspectos relevantes. Em primeiro lugar, o planejamento do país esteve sempre condicionado às condições políticas subjacentes, que no decorrer do período apresentaram forte instabilidade, convivendo com situações conjunturais que conduziram a uma intensa participação estatal, tanto na esfera da coordenação geral quanto na da produção. As discussões presentes na atualidade, sobre a predominância do liberalismo econômico ou da forte intervenção estatal, revelam um período de relevantes transformações quanto à noção do grau de intervenção apropriado às condições do país.

Por outro lado, o planejamento governamental deve ser entendido como um processo contínuo, que envolve desde a elaboração de um plano, até sua implementação, controle e ajustamentos. Nesse sentido, a consecução dos objetivos formulados está diretamente relacionada à verificação, não apenas da consistência global do plano, mas também da capacidade de execução efetiva das políticas públicas previstas, sem desvios consideráveis dos objetivos iniciais. O que se observou, na maior parte dos planos postos em prática, foi a incapacidade da continuação do processo em toda a sua trajetória, dadas as dificuldades técnicas como falta de qualificação dos recursos humanos, insuficiência de infra-estrutura e mesmo de controle efetivo, que sobrepujaram a insuficiência de recursos financeiros ou a instabilidade política crônica. Particularmente os planos postos em prática a partir da década de 80 , dadas as condições econômicas conjunturais do país, tiveram a característica de se dedicarem especificamente à estabilização da economia e, portanto, por natureza, se apresentarem como parciais e com a preocupação prioritária de curto prazo, sem a globalidade e abrangência de um plano de desenvolvimento. 